\title{
Safety and feasibility of minimally invasive surgical interventions for esophageal and gastric cancer in the acute setting: a nationwide cohort study
}

\author{
Alicia S. Borggreve ${ }^{1,2} \cdot$ B. Feike Kingma ${ }^{1}$ Jelle P. Ruurda ${ }^{1} \cdot$ Richard van Hillegersberg $^{1} \cdot$ the Dutch Upper G.I. Cancer \\ Audit (DUCA) group
}

Received: 30 January 2019 / Accepted: 2 March 2020 / Published online: 25 March 2020

(c) The Author(s) 2020

\begin{abstract}
Background Minimally invasive esophagectomy and gastrectomy are increasingly performed and might be superior to their open equivalents in an elective setting. The aim of this study was to evaluate whether minimally invasive approaches can be safely applied in the acute setting as well.

Methods All patients who underwent an acute surgical intervention for primary esophageal or gastric cancer between 2011 and 2017 were identified from the nationwide database of the Dutch Upper GI Cancer Audit (DUCA). Conversion rates, postoperative complications, re-interventions, postoperative mortality, hospital stay and oncological outcomes (radical resection rates and median lymph node yield) were evaluated.

Results Between 2011 and 2017, surgery for esophagogastric cancer was performed in an acute setting in 2\% (190/8861) in The Netherlands. A total of 14 acute resections for esophageal cancer were performed, which included 7 minimally invasive esophagectomies and 7 open esophagectomies. As these numbers were very low, no comparison between minimally invasive and open esophagectomies was made. A total of 122 acute resections for gastric cancer were performed, which included 39 minimally invasive gastrectomies and 83 open gastrectomies. Conversion occurred in 9 patients (23\%). Minimally invasive gastrectomy was at least comparable to open gastrectomy regarding postoperative complications (36\% versus 51\%), median hospital stay ( 9 days [IQR: $7-16$ days] versus 11 days [IQR: 7-17 days]), readmissions (8\% versus 11\%) and oncological outcomes (radical resection rate: 87\% versus 66\%, median lymph node yield: 21 [IQR: 15-32 days] versus 16 [IQR: 11-24 days]).

Conclusions Minimally invasive surgery for gastric cancer is safe and feasible in the acute setting, with at least comparable postoperative clinical and short-term oncological outcomes compared to open surgery but a relatively high conversion rate.
\end{abstract}

Keywords Esophageal cancer · Gastric cancer · Acute surgery · Minimally invasive surgery · Open surgery · Postoperative complications · Oncological outcomes

Minimally invasive surgical techniques are increasingly being applied in the surgical treatment of esophageal and gastric cancer [1, 2]. Evidence from randomized controlled trials and nationwide studies suggests that these techniques

Richard van Hillegersberg

R.vanHillegersberg@umcutrecht.nl

1 Department of Surgery, University Medical Center Utrecht, Utrecht University, Heidelberglaan 100, 3584 CX Utrecht, The Netherlands

2 Department of Radiation Oncology, University Medical Center Utrecht, Utrecht University, Heidelberglaan 100, 3584 CX Utrecht, The Netherlands might provide benefits over the traditional open approaches, especially regarding short-term outcomes in terms of postoperative morbidity and length of hospital stay [3-12]. In contrast, higher reintervention rates were observed after minimally invasive esophagectomies in population-based studies [5-8]. As the aforementioned studies only included patients who underwent an elective surgical resection, the generalizability of these results to the acute setting might be limited.

Acute surgery for esophageal and gastric cancer is relatively rare and is usually only performed in case tumors are actively bleeding or have perforated. These cases are different from the usual elective patient population and might 
therefore be more difficult to treat with minimally invasive surgical techniques. More research is warranted to investigate the role of minimally invasive surgical techniques for patients with esophageal and gastric cancer who have an acute indication for a resection. Therefore, the aim of this nationwide cohort study was to describe the postoperative outcomes of minimally invasive as compared to open acute surgery for esophageal and gastric cancer.

\section{Methods}

\section{Study design}

This nationwide observational cohort study was conducted with data from the Dutch Upper GI Cancer Audit (DUCA), a nationwide registration of all patients undergoing surgery for esophageal and gastric cancer since 2011 [13]. Registration of cases in the DUCA is mandatory for each hospital and includes patient characteristics, treatment details including the timing of surgery, postoperative outcomes (until 30 days after surgery), and pathological outcomes. The scientific committee of the DICA and DUCA approved this study. No ethical approval or informed consent was required under Dutch law.

\section{Study population and treatment}

All patients who underwent acute surgery with the intention to perform an esophagectomy or gastrectomy for cancer between 2011 and 2017 were selected from the DUCA registry. Patients were diagnosed according to the Dutch national guidelines for diagnosis, treatment, follow up, and guidance of patients for patients with esophageal and gastric cancer $[14,15]$. Acute surgical interventions were either defined as emergent (i.e., surgery scheduled $<12 \mathrm{~h}$ after presentation with an acute indication) or urgent (surgery scheduled $>12 \mathrm{~h}$-but not electively-after presentation with an acute indication). Both were included in the current study. Exclusion criteria were prophylactic surgical indications (i.e., no proven malignancy), insufficient data regarding the tumor or surgical approach, and surgery for cancer recurrence.

\section{Outcome measures}

The outcome measures included the rates of conversion to an open procedure, postoperative complications, re-interventions, postoperative mortality (i.e., mortality during initial hospital admission or within 30 days after surgery), length of postoperative stay on the Intensive Care Unit (ICU) and in hospital, as well as readmissions $(<30$ days after discharge). Complications were defined according to standards of the DUCA, and included pulmonary complications (clinically proven pneumonia, pleural effusion leading to drainage, pleural empyema and/or acute respiratory distress syndrome), anastomotic leakage (either by clinical or radiological diagnosis), cardiac complications (supraventricular and ventricular arrhythmia, myocardial infarction and/or heart failure), thromboembolic complications (pulmonary embolism, deep venous thrombosis, stroke and/or thrombophlebitis), neurologic complications (recurrent laryngeal nerve injury and/or acute delirium), urologic complications (urinary tract infection, urinary retention and/or renal insufficiency), intra-abdominal abscess, chyle leakage, fascia dehiscence and wound infections. Furthermore, oncological outcomes in terms of radicality and total lymph node yield were analyzed. A radical resection (i.e., R0) was defined as the absence of tumor cells within the resection margins of the resection specimen.

\section{Statistical analyses}

Patient and treatment characteristics were described as counts with percentages, mean ( \pm standard deviation $[\mathrm{SD}]$ ) or median (interquartile range [IQR]). The postoperative outcomes were separately described for patients who underwent minimally invasive surgery and open surgery. No tests for statistical significance of differences between groups were performed because of inability to adequately correct for confounding bias due to small group sizes. Statistical analyses were performed using SPSS 23.0 (IBM Corp., Armonk, NY, USA).

\section{Results}

\section{Study population}

Between 2011 and 2017, a total of 8861 patients who underwent surgery for esophageal or gastric cancer in the Netherlands were registered in the DUCA. Surgery was performed in an acute setting in 190 out of these 8861 patients (2\%). Patients who underwent an unspecified surgical intervention $(n=5)$, a surgical procedure for cancer recurrence $(n=3)$, or a surgical procedure for an unspecified malignancy $(n=6)$ were excluded. Hence, a total of 176 patients were included, of whom 17 patients with esophageal cancer and 159 patients with gastric cancer (Fig. 1).

\section{Acute surgical interventions for esophageal cancer}

Acute surgical interventions for esophageal cancer were performed in 17 patients and were with curative intent in all of these patients. The median number of days between the diagnostic biopsy and surgery was 70 days (IQR 46-121 days). 
Fig. 1 Study flowchart

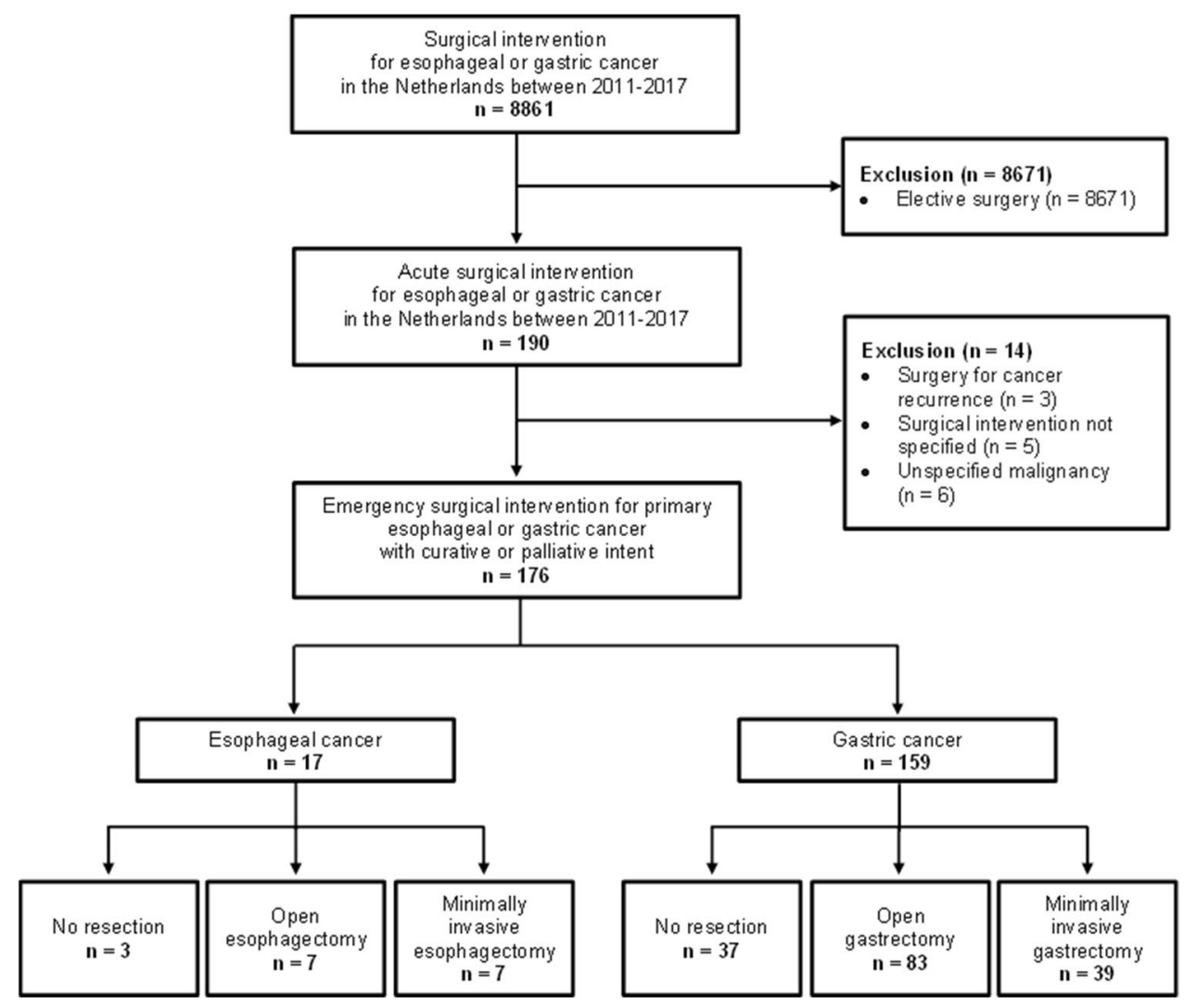

In 2 patients (12\%), no histologic diagnosis was present prior to surgery. The reason for surgery was a perforation in 7 patients $(41 \%)$, bleeding in 5 patients $(29 \%)$ and other (not specified) in the remaining 5 cases (29\%). Esophagectomy was performed in 14 out of these 17 patients (82\%); by a minimally invasive transhiatal approach in 4 patients, an open transhiatal approach in 5 patients, a minimally invasive transthoracic approach in 3 patients, and an open transthoracic approach in 2 patients. The remaining 3 patients (18\%) underwent a surgical procedure without resection, which involved a diagnostic laparoscopy in 2 patients and a diagnostic thoracotomy in 1 patient. A complete overview of patient and treatment characteristics of the esophageal cancer patients is presented in Table 1.

Perioperative and oncological outcomes of the 14 patients who underwent esophagectomy are shown in Table 2. The outcomes were not reported for minimally invasive esophagectomy and open esophagectomy separately, as the number of patients for both groups was only 7 . Postoperative complications occurred in 50\% (7/14). Pulmonary complications were most common $(43 \%, 6 / 14)$, followed by anastomotic leakage $(29 \%, 4 / 14)$. The median length of hospital stay was 13 days (IQR: 11-26 days). No patients were readmitted to the hospital within 30 days after discharge.
Histopathological evaluation of the resection specimen showed that a radical resection was achieved in 64\% (9/14). The median lymph node yield was 21 (IQR: 12-26 days).

\section{Acute surgical interventions for gastric cancer}

An acute surgical intervention for gastric cancer was performed in 159 patients, with an upfront curative intent in the majority of patients $(70 \%)$. The median time between diagnostic biopsy and acute surgery was 23 days (IQR 11-36 days). Histological confirmation of gastric cancer was not present prior to surgery in 25 patients $(16 \%)$. The reason for surgery was a bleeding in 68 patients $(43 \%)$, perforation in 19 patients $(12 \%)$ and other (not specified) in the remaining 73 patients (46\%). Gastrectomy was performed in 122 patients (77\%), which was by a minimally invasive approach in 39 patients and by an open approach in 83 patients. The remaining 37 patients (23\%) underwent a surgical procedure without resection, which involved a gastroenterostomy in 26 patients, diagnostic laparoscopy in 6 patients and a diagnostic laparotomy in 5 patients. Most minimally invasive procedures were observed in the more recent years (Fig. 2). A complete overview of patient and treatment-related characteristics of the gastric cancer patients is presented in Table 3 .

Perioperative and oncological outcomes of the 122 patients who underwent a gastrectomy are shown in 
Table 1 Baseline characteristics of patients who underwent an acute surgical intervention for esophageal cancer in the Netherlands between 2011 and 2017

\begin{tabular}{lll}
\hline Characteristics & All & \\
\cline { 2 - 3 }$n=17$ & $\%$
\end{tabular}

Patient-related characteristics

\begin{tabular}{|c|c|c|}
\hline \multirow{2}{*}{$\begin{array}{l}\text { Age, years }(\text { mean } \pm S D) \\
\text { Sex }\end{array}$} & \multicolumn{2}{|l|}{$64 \pm 11$} \\
\hline & & \\
\hline Male & 15 & $88 \%$ \\
\hline Female & 2 & $12 \%$ \\
\hline $\mathrm{BMI}, \mathrm{kg} / \mathrm{m}^{2}(\operatorname{mean} \pm \mathrm{SD})$ & $26 \pm 5$ & \\
\hline \multicolumn{3}{|l|}{ ASA classification } \\
\hline I & 2 & $12 \%$ \\
\hline II & 7 & $41 \%$ \\
\hline III & 7 & $41 \%$ \\
\hline IV & 1 & $6 \%$ \\
\hline \multicolumn{3}{|l|}{ Comorbidities } \\
\hline Cardiac & 2 & $12 \%$ \\
\hline Vascular & 8 & $47 \%$ \\
\hline Diabetes & 5 & $29 \%$ \\
\hline Pulmonary & 3 & $18 \%$ \\
\hline Previous abdominal or thoracic surgery & 7 & $41 \%$ \\
\hline \multicolumn{3}{|l|}{ Tumor location } \\
\hline Middle esophagus & 1 & $6 \%$ \\
\hline Distal esophagus & 9 & $53 \%$ \\
\hline Gastro-esophageal junction & 5 & $29 \%$ \\
\hline Unknown & 2 & $12 \%$ \\
\hline \multicolumn{3}{|l|}{ Histology } \\
\hline Adenocarcinoma & 15 & $88 \%$ \\
\hline Squamous cell carcinoma & 1 & $6 \%$ \\
\hline Other & 1 & $6 \%$ \\
\hline \multicolumn{3}{|l|}{ cT status ${ }^{\mathrm{a}}$} \\
\hline $\mathrm{T} 1$ & 3 & $18 \%$ \\
\hline $\mathrm{T} 2$ & 2 & $12 \%$ \\
\hline $\mathrm{T} 3$ & 5 & $29 \%$ \\
\hline $\mathrm{T} 4$ & 5 & $29 \%$ \\
\hline $\mathrm{Tx}$ & 2 & $12 \%$ \\
\hline \multicolumn{3}{|l|}{$\mathrm{cN}$ status ${ }^{\mathrm{a}}$} \\
\hline N0 & 6 & $35 \%$ \\
\hline $\mathrm{N}+$ & 8 & $47 \%$ \\
\hline $\mathrm{Nx}$ & 3 & $18 \%$ \\
\hline \multicolumn{3}{|l|}{$\mathrm{cM}_{\text {status }}^{\mathrm{a}}$} \\
\hline M0 & 13 & $76 \%$ \\
\hline M1 & 2 & $12 \%$ \\
\hline $\mathrm{Mx}$ & 2 & $12 \%$ \\
\hline \multicolumn{3}{|l|}{ Treatment-related characteristics } \\
\hline \multicolumn{3}{|l|}{ Neoadjuvant therapy ${ }^{\mathrm{b}}$} \\
\hline None & 10 & $59 \%$ \\
\hline Chemoradiotherapy & 4 & $24 \%$ \\
\hline Chemotherapy & 2 & $12 \%$ \\
\hline Radiotherapy & 1 & $6 \%$ \\
\hline
\end{tabular}

Table 1 (continued)

\begin{tabular}{|c|c|c|}
\hline \multirow[t]{2}{*}{ Characteristics } & \multicolumn{2}{|l|}{ All } \\
\hline & $n=17$ & $\%$ \\
\hline \multicolumn{3}{|l|}{ Setting } \\
\hline Emergent $(<12 \mathrm{~h})$ & 10 & $59 \%$ \\
\hline Urgent (> $12 \mathrm{~h})$ & 8 & $41 \%$ \\
\hline \multicolumn{3}{|l|}{ Reason for emergency surgery } \\
\hline Bleeding & 5 & $29 \%$ \\
\hline Perforation & 7 & $41 \%$ \\
\hline Other/unknown & 5 & $29 \%$ \\
\hline \multicolumn{3}{|l|}{ Surgical approach } \\
\hline Minimally invasive & 9 & $53 \%$ \\
\hline Open & 8 & $47 \%$ \\
\hline \multicolumn{3}{|l|}{ Surgical procedure } \\
\hline Transhiatal esophagectomy & 9 & $53 \%$ \\
\hline Transthoracic esophagectomy & 5 & $29 \%$ \\
\hline Diagnostic thoracotomy & 1 & $6 \%$ \\
\hline Diagnostic laparoscopy & 2 & $12 \%$ \\
\hline \multicolumn{3}{|l|}{ Reconstruction } \\
\hline Gastric conduit reconstruction & 12 & $71 \%$ \\
\hline No reconstruction & 4 & $24 \%$ \\
\hline Unknown & 1 & $6 \%$ \\
\hline \multicolumn{3}{|l|}{ Location of anastomosis } \\
\hline Cervical & 10 & $59 \%$ \\
\hline Intrathoracic & 2 & $12 \%$ \\
\hline Not applicable & 5 & $29 \%$ \\
\hline Lymph node dissection & 13 & $76 \%$ \\
\hline \multicolumn{3}{|l|}{ Year of surgery } \\
\hline 2011-2013 & 9 & $53 \%$ \\
\hline 2014-2017 & 8 & $47 \%$ \\
\hline
\end{tabular}

Data are numbers of patients with column-based percentages in parentheses, unless otherwise stated

ASA American Society of Anesthesiologists; BMI body mass index at diagnosis; $S D$ standard deviation

${ }^{\mathrm{a} C l i n i c a l} \mathrm{~T}$ status and $\mathrm{N}$ status are based on AJCC TNM 7th edition

${ }^{\mathrm{b}}$ The standard regimen for neoadjuvant treatment for esophageal cancer patients in the Netherlands consists of carboplatin and paclitaxel, weekly during 5 weeks, and concurrent radiotherapy with a total radiation dose of $41.4 \mathrm{~Gy}$ in 23 fractions of $1.8 \mathrm{~Gy}$. For gastro-esophageal junction or gastric adenocarcinoma, peri-operative treatment generally consists of chemotherapy regimens similar to the MAGIC-trial (epirubicin, cisplatin and capecitabine)

Table 4. Conversion to an open procedure occurred in 9 of the 39 minimally invasive gastrectomies (23\%), mostly because of the extent of the tumor and poor exposure (Table 4). Postoperative complications occurred in 14 of the 39 patients who underwent a minimally invasive gastrectomy (36\%) and in 42 of the 83 patients who underwent an open gastrectomy (51\%). When comparing minimally invasive gastrectomy versus open gastrectomy, pulmonary complications occurred in $13 \%$ versus $18 \%$, anastomotic 
Table 2 Short-term outcomes for patients who underwent an acute esophagectomy for esophageal cancer in the Netherlands between 2011 and 2017

\begin{tabular}{|c|c|c|}
\hline & \multicolumn{2}{|l|}{ Total } \\
\hline & $n=14$ & $\%$ \\
\hline \multicolumn{3}{|l|}{ Peroperative outcomes } \\
\hline Conversion $^{\mathrm{a}}$ & 1 & $7 \%$ \\
\hline \multicolumn{3}{|l|}{ Postoperative complications } \\
\hline All & 7 & $50 \%$ \\
\hline Pulmonary ${ }^{\mathrm{b}}$ & 6 & $43 \%$ \\
\hline Anastomotic leakage $^{c}$ & 4 & $29 \%$ \\
\hline Cardiac $^{\mathrm{d}}$ & 1 & $7 \%$ \\
\hline Chyle leakage & 0 & $0 \%$ \\
\hline Re-interventions & $1^{\mathrm{g}}$ & $7 \%$ \\
\hline \multicolumn{3}{|l|}{ Recovery } \\
\hline ICU duration (median, IQR) & 3 & $(1-6)$ \\
\hline Length of stay (median, IQR) & 13 & $(11-26)$ \\
\hline Postoperative mortality ${ }^{\mathrm{e}}$ & 1 & $7 \%$ \\
\hline Readmission to hospital $^{\mathrm{f}}$ & 0 & $0 \%$ \\
\hline \multicolumn{3}{|l|}{ Pathological outcomes } \\
\hline \multicolumn{3}{|l|}{ Radicality } \\
\hline R0 & 9 & $64 \%$ \\
\hline $\mathrm{R} 1$ & 5 & $36 \%$ \\
\hline Lymph node yield (median, IQR) & 21 & $(12-26)$ \\
\hline $\begin{array}{l}\text { Positive lymph nodes harvested (median, } \\
\text { IQR) }\end{array}$ & 3 & $(1-10)$ \\
\hline
\end{tabular}

There were no missing values for the variables described in this table $I Q R$ interquartile range, $N A$ not applicable

${ }^{\mathrm{a} C o n v e r s i o n}>30$ min after start of surgery because of peroperative bleeding

${ }^{\mathrm{b}}$ Pneumonia, pleural effusion, respiratory failure, pneumothorax and/ or acute respiratory distress syndrome

${ }^{\mathrm{c}}$ Any clinically or radiologically proven anastomotic leakage

${ }^{\mathrm{d}}$ Supraventricular and ventricular arrhythmia, myocardial infarction and/or heart failure

${ }^{\mathrm{e}}$ Death during initial hospital admission or within 30 days after surgery

${ }^{\mathrm{f}}$ Readmission to hospital within 30 days after initial discharge

${ }^{\mathrm{g}}$ Re-operation for anastomotic leakage

leakage in $8 \%$ versus $8 \%$, and wound infection in $0 \%$ versus $13 \%$, respectively. Re-interventions, mostly for anastomotic leakage in both groups, were performed in $23 \%$ after a minimally invasive gastrectomy versus $14 \%$ after an open gastrectomy. Postoperative mortality occurred in $8 \%$ after a minimally invasive gastrectomy versus $11 \%$ after an open gastrectomy. The median length of hospital stay was 9 days (IQR: 7-16 days) after minimally invasive gastrectomy versus 11 days (IQR: 7-17 days) after open gastrectomy. Readmission to the hospital was seen in $8 \%$ after minimally invasive gastrectomy versus $11 \%$ after open gastrectomy.
A Surgical interventions for gastric cancer $(n=159)$

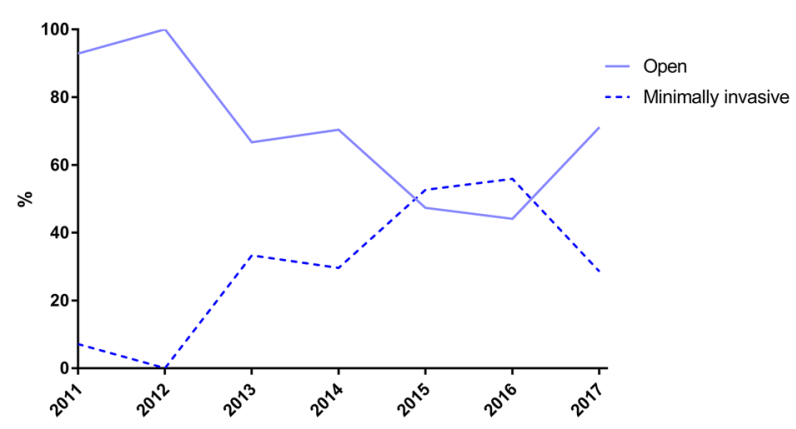

\begin{tabular}{|llllllll|}
\hline Numbers & & & & & & & \\
Open & 13 & 16 & 28 & 19 & 9 & 15 & 5 \\
Minimally invasive & 1 & 0 & 14 & 8 & 10 & 19 & 2 \\
\hline
\end{tabular}
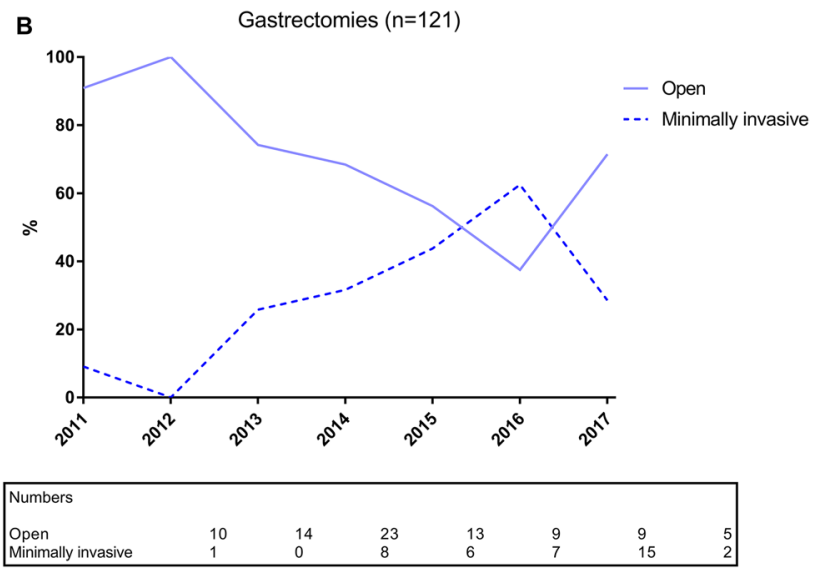

Fig. 2 Minimally invasive and open surgical interventions (A) and gastrectomies (B) for acute presentation of gastric cancer in the study period

Histopathological evaluation of the resection specimen showed that a radical resection was achieved in 34 of the minimally invasive gastrectomies (87\%) and in 55 of the open gastrectomies (66\%). The median lymph node yield was 21 (IQR: 15-32 days) after minimally invasive gastrectomy and 16 (IQR: 11-24 days) after open gastrectomy.

\section{Discussion}

In this nationwide cohort study concerning patients who underwent acute surgery for esophageal and gastric cancer, short-term postoperative and oncological outcomes of minimally invasive resections were comparable to open resections..

Previous studies have shown the safety and feasibility of minimally invasive surgery for esophagogastric cancer in the elective setting [3-12]. For esophageal cancer, minimally invasive esophagectomy resulted in a shorter hospital stay, higher lymph node yield, similar radical resection rate and 
Table 3 Baseline characteristics of patients who underwent an acute surgical intervention for gastric cancer in the Netherlands between 2011 and 2017

\begin{tabular}{|c|c|c|c|c|}
\hline \multirow[t]{2}{*}{ Characteristics } & \multicolumn{2}{|l|}{ Open } & \multicolumn{2}{|c|}{$\begin{array}{l}\text { Minimally } \\
\text { invasive }\end{array}$} \\
\hline & $n=105$ & $\%$ & $n=54$ & $\%$ \\
\hline \multicolumn{5}{|l|}{ Patient-related characteristics } \\
\hline Age, years $($ mean $\pm S D)$ & \multicolumn{2}{|l|}{$71 \pm 10$} & \multicolumn{2}{|l|}{$71 \pm 12$} \\
\hline \multicolumn{5}{|l|}{ Sex } \\
\hline Male & 79 & 75 & 33 & 61 \\
\hline Female & 26 & 25 & 21 & 39 \\
\hline BMI, $\mathrm{kg} / \mathrm{m}^{2}($ mean $\pm \mathrm{SD})$ & \multicolumn{2}{|l|}{$25 \pm 4$} & \multicolumn{2}{|l|}{$25 \pm 4$} \\
\hline \multicolumn{5}{|l|}{ ASA classification } \\
\hline I & 8 & 8 & 2 & 4 \\
\hline II & 39 & 37 & 25 & 46 \\
\hline III & 46 & 44 & 23 & 43 \\
\hline IV & 7 & 7 & 4 & 7 \\
\hline $\mathrm{V}$ & 1 & 1 & 0 & 0 \\
\hline Not specified & 4 & 4 & 0 & 0 \\
\hline \multicolumn{5}{|l|}{ Comorbidities } \\
\hline Cardiac & 35 & 33 & 24 & 44 \\
\hline Vascular & 42 & 40 & 27 & 50 \\
\hline Diabetes & 22 & 21 & 10 & 19 \\
\hline Pulmonary & 23 & 22 & 11 & 20 \\
\hline $\begin{array}{l}\text { Previous abdominal or thoracic } \\
\text { surgery }\end{array}$ & 37 & 35 & 18 & 33 \\
\hline \multicolumn{5}{|l|}{ Tumor location } \\
\hline Fundus & 6 & 6 & 3 & 6 \\
\hline Corpus & 28 & 27 & 12 & 22 \\
\hline Antrum & 48 & $46 \%$ & 22 & 41 \\
\hline Pylorus & 12 & 11 & 12 & 22 \\
\hline Stomach & 3 & 3 & 2 & 4 \\
\hline Other/not specified & 8 & 8 & 3 & 6 \\
\hline \multicolumn{5}{|l|}{ Histology } \\
\hline Adenocarcinoma & 88 & 84 & 49 & 91 \\
\hline Other & 8 & 8 & 4 & 7 \\
\hline Not specified & 9 & 8 & 1 & 2 \\
\hline \multicolumn{5}{|l|}{ cT status $^{\mathrm{a}}$} \\
\hline $\mathrm{T} 1$ & 4 & 4 & 2 & 4 \\
\hline $\mathrm{T} 2$ & 8 & 8 & 8 & 15 \\
\hline $\mathrm{T} 3$ & 32 & 30 & 20 & 37 \\
\hline $\mathrm{T} 4$ & 18 & 17 & 10 & 19 \\
\hline $\mathrm{Tx}$ & 43 & 41 & 13 & 24 \\
\hline \multicolumn{5}{|l|}{$\mathrm{cN}_{\text {status }}{ }^{\mathrm{a}}$} \\
\hline N0 & 26 & 25 & 19 & 35 \\
\hline $\mathrm{N}+$ & 46 & 44 & 28 & 52 \\
\hline $\mathrm{Nx}$ & 33 & 31 & 7 & 13 \\
\hline \multicolumn{5}{|l|}{$\mathrm{cM}_{\text {status }}{ }^{\mathrm{a}}$} \\
\hline M0 & 76 & 72 & 44 & 81 \\
\hline M1 & 9 & 9 & 4 & 7 \\
\hline Mx & 20 & 19 & 6 & 11 \\
\hline
\end{tabular}

Table 3 (continued)

\begin{tabular}{|c|c|c|c|c|}
\hline \multirow[t]{2}{*}{ Characteristics } & \multicolumn{2}{|l|}{ Open } & \multicolumn{2}{|c|}{$\begin{array}{l}\text { Minimally } \\
\text { invasive }\end{array}$} \\
\hline & $n=105$ & $\%$ & $n=54$ & $\%$ \\
\hline \multicolumn{5}{|l|}{ Treatment-related characteristics } \\
\hline \multicolumn{5}{|l|}{ Neoadjuvant therapy ${ }^{\mathrm{b}}$} \\
\hline None & 93 & 89 & 52 & 96 \\
\hline Chemotherapy & 11 & 10 & 2 & 4 \\
\hline Chemoradiotherapy & 1 & 1 & 0 & 0 \\
\hline \multicolumn{5}{|l|}{ Setting } \\
\hline Emergent $(<12 \mathrm{~h})$ & 37 & 35 & 8 & 15 \\
\hline Urgent (> $12 \mathrm{~h})$ & 68 & 65 & 46 & 85 \\
\hline \multicolumn{5}{|l|}{ Reason for acute surgery } \\
\hline Bleeding & 41 & $39 \%$ & 26 & 48 \\
\hline Perforation & 17 & $16 \%$ & 2 & 4 \\
\hline Other & 47 & $45 \%$ & 26 & 48 \\
\hline \multicolumn{5}{|l|}{ Surgical procedure } \\
\hline Total gastrectomy & 26 & $25 \%$ & 8 & 15 \\
\hline Partial gastrectomy & 57 & $54 \%$ & 31 & 57 \\
\hline Bypass (gastroenterostomy) & 17 & $16 \%$ & 9 & 17 \\
\hline Diagnostic laparotomy/laparoscopy & 5 & $5 \%$ & 6 & 11 \\
\hline \multicolumn{5}{|l|}{ Intention } \\
\hline Curative intent & 74 & $70 \%$ & 43 & 80 \\
\hline Palliative intent & 26 & $25 \%$ & 8 & 15 \\
\hline Not specified & 5 & $5 \%$ & 3 & 6 \\
\hline Lymph node dissection & 64 & $61 \%$ & 35 & 65 \\
\hline \multicolumn{5}{|l|}{ Year of surgery } \\
\hline 2011-2013 & 57 & $54 \%$ & 15 & 28 \\
\hline 2014-2017 & 48 & $46 \%$ & 39 & 72 \\
\hline
\end{tabular}

Data are numbers of patients with column-based percentages in parentheses, unless otherwise stated

ASA American Society of Anesthesiologists; BMI body mass index at diagnosis; $S D$ standard deviation

${ }^{\mathrm{a}}$ Clinical $\mathrm{T}$ status and $\mathrm{N}$ status are based on AJCC TNM 7th edition

${ }^{\mathrm{b}}$ The standard regimen for peri-operative treatment for gastro-esophageal junction or gastric adenocarcinoma generally consists of chemotherapy regimens similar to the MAGIC-trial (epirubicin, cisplatin and capecitabine)

postoperative pulmonary complications, but higher reintervention rates in several population-based studies [5-8]. Due to the low number of acute esophagectomies, it was unfortunately not possible in this study to perform the analyses that would be required to reproduce these results for minimally invasive esophagectomy in the acute setting. For gastric cancer, minimally invasive gastrectomy in the elective setting was deemed to be safe and feasible regarding overall postoperative morbidity and mortality rates, as well as short-term oncological outcomes, and resulted in decreased wound complications and a shorter hospital stay compared to open gastrectomy $[10,12]$. The current study of minimally invasive gastrectomy in the acute setting also 


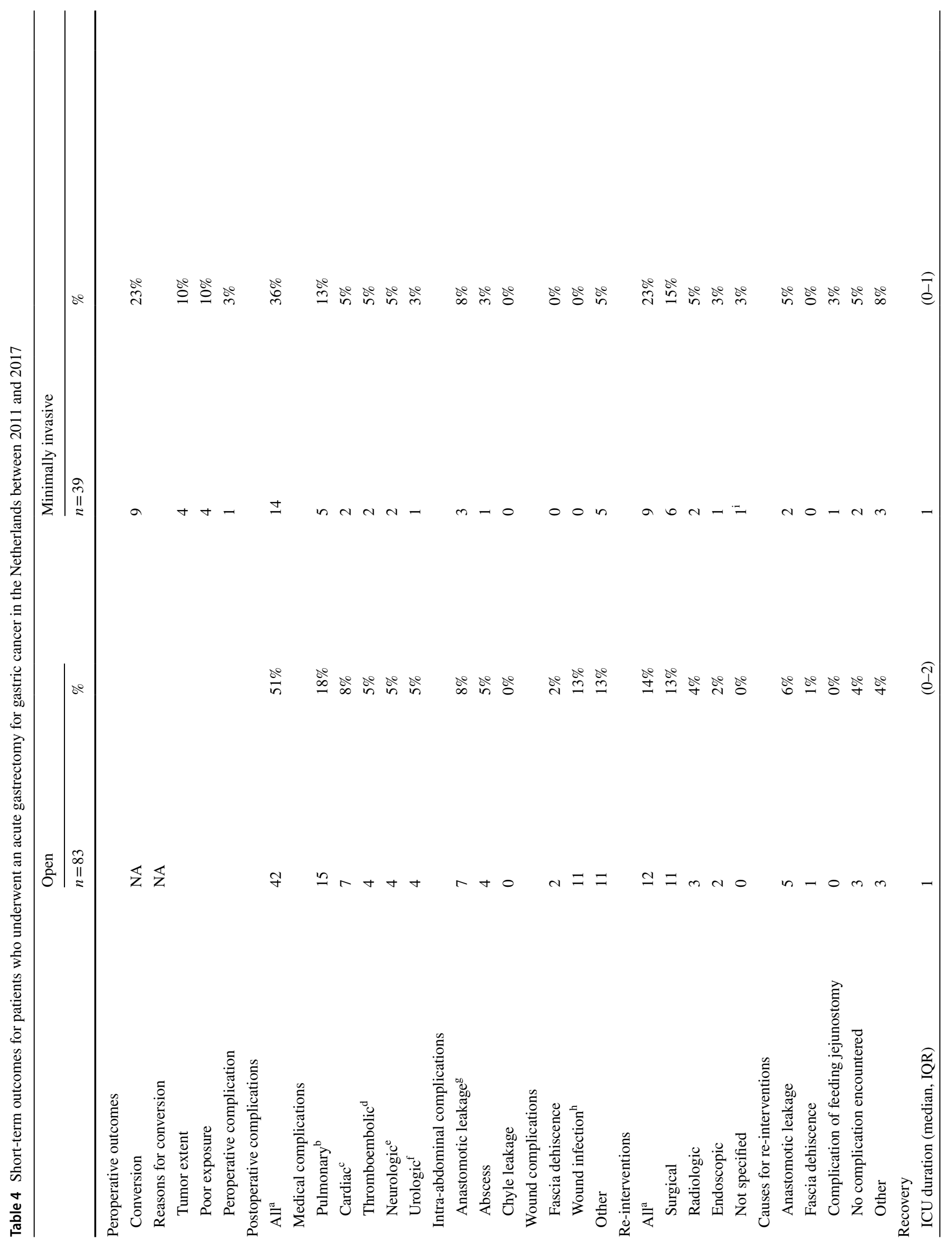




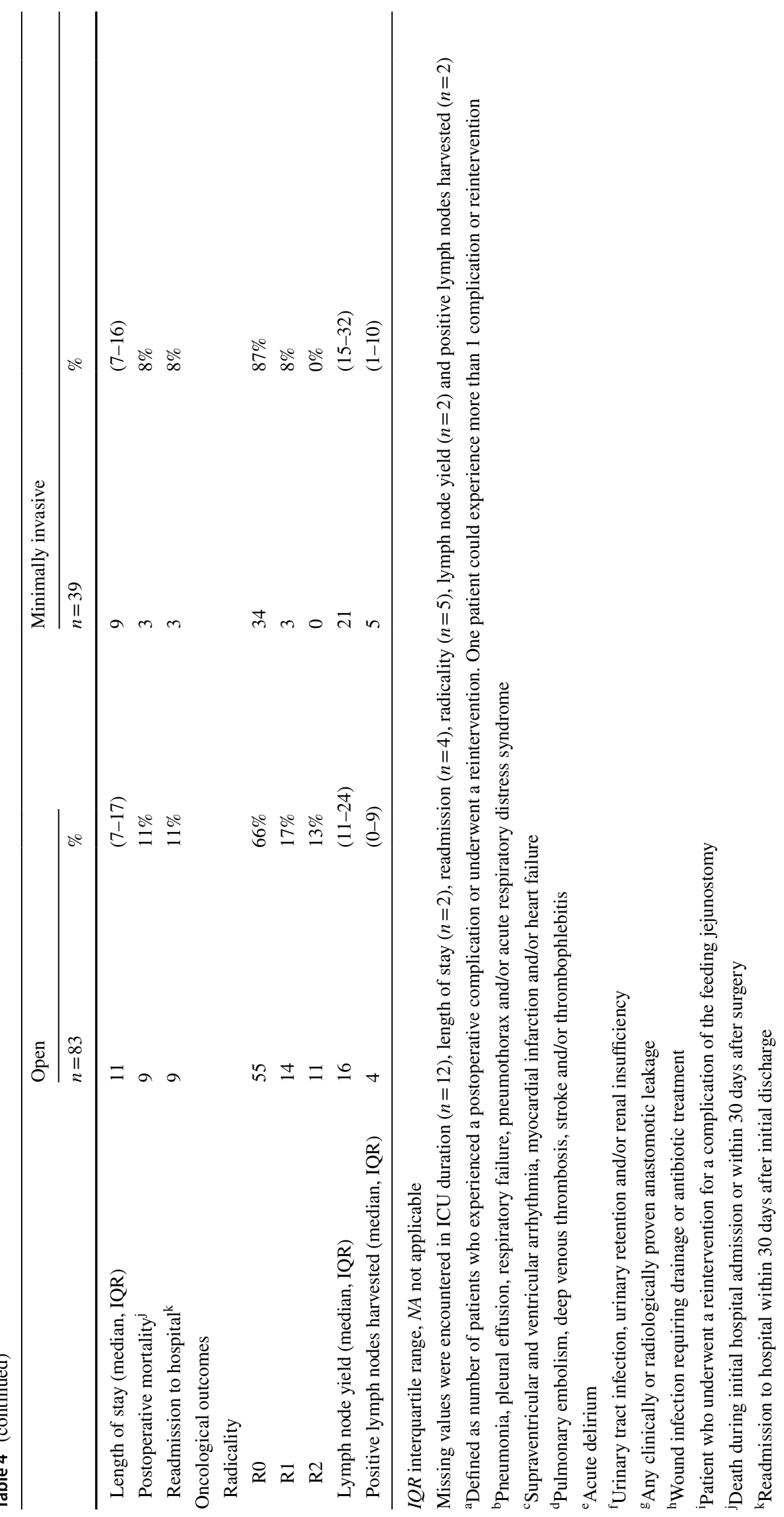


demonstrated comparable oncological outcomes to the open approach, as well as a potentially decreased median length of hospital stay. However, the current study demonstrated a higher conversion rate of minimally invasive gastrectomies in the acute setting (23\% versus $0.9 \%$ [12], 3.5\% [11] and $10 \%$ [10] in the elective setting), as well as a potentially increased percentage of patients that underwent a reintervention after minimally invasive gastrectomy (23\% versus $14 \%$ in the acute setting and $0.4 \%$ versus $0.4 \%$ [11], $1.2 \%$ versus $1.5 \%$ [12] and $17 \%$ versus $16 \%$ [10] in the elective setting for minimally invasive gastrectomy versus open gastrectomy, respectively). Unfortunately, no clear explanation for this difference could be deduced from the causes for the re-interventions as available in the data.

In order to correctly interpret the current results, it must be noted that esophagogastric cancer surgery has been centralized since 2011 in the Netherlands. This is one of the main reasons that $84 \%$ of the elective esophagectomies and $40 \%$ of the elective gastrectomies are performed by minimally invasive techniques in the recent years [6,9]. A similar increase has been seen for the use of minimally invasive techniques in the acute setting. Most surgeons in the Netherlands implemented these techniques after participating in a hands-on course on minimally invasive esophagectomy and gastrectomy, followed by several cases with an experienced surgeon present. The influence of centralization and learning curves on postoperative outcomes also seem to be important in for esophagogastric surgery in the acute setting, as demonstrated by a recently published study from England [16]. High-volume cancer centers and surgeons are more experienced in managing patients following esophagectomy and gastrectomy, and have the appropriate infrastructure available [16]. As such, they might be better equipped to deliver consistent levels of high-quality outcomes for minimally invasive surgery in the acute setting as well which might explain the comparable outcomes for minimally invasive and open surgery in the current study.

Overall, acute surgical interventions for upper gastrointestinal malignancies are rare, accounting for only $2 \%$ of all surgical interventions for upper gastrointestinal malignancies in the Netherlands. This especially applies for surgical interventions for esophageal cancer, occurring approximately once yearly in a country with an incidence of approximately 2500 new esophageal cancer cases per year [17]. Interestingly, most patients who underwent an acute surgical intervention had prior histological confirmation of their cancer diagnosis, indicating that patients generally did not present with an acute symptom of an unknown malignancy. The majority of the gastric cancer cases had a cause for acute intervention other than bleeding or perforation. As the DUCA registry only registers the indication for acute intervention in 3 prespecified categories (bleeding, perforation and other), the frequency of obstruction as another important indication for acute surgical interventions in gastric cancer could not be researched. However, in patients with an obstruction, a gastroenterostomy or distal gastrectomy might have been more frequently performed. When the surgical procedures of patients without a specified reason for the surgical intervention are explored in more detail, it might indeed be that obstruction accounts for a large share of the not specified indications, as $30 \%$ of them underwent a gastroenterostomy $(21 / 71)$ and $44 \%$ underwent a partial gastrectomy (31/71) (data not shown).

The population-based design with virtually complete inclusion of all patients in the Netherlands is a significant strength of the study, along with the prospective data collection and detailed information on strictly defined postoperative outcomes. However, there are some limitations of the current study that need to be addressed. First, the small numbers of patients in all groups precluded a direct comparison between minimally invasive and open surgery correcting for bias. This prevents firm conclusions to be drawn regarding the potentially observed benefits of minimally invasive compared to open surgery in the acute setting (e.g., the decreased median length of hospital stay, higher observed percentage of radical resections and increased median lymph node yield), as well as regarding the potential disadvantages of minimally invasive surgery (e.g., the increased percentage of re-interventions after minimally invasive gastrectomy compared to open gastrectomy). Second, the introduction of minimally invasive surgery for upper gastrointestinal malignancies occurred simultaneously with centralization of cancer care and the introduction of enhanced recovery after surgery (ERAS) programs in the Netherlands. It has been shown that centralization of surgery is associated with reduced complications and improved long-term survival [18-21] and that the use of ERAS programs protocols can reduce the length of hospital stay $[22,23]$. As such, the observed outcomes in this study for both minimally invasive as open surgery are probably influenced by these factors. It must be further acknowledged as a limitation that, due to the privacy restrictions of the national database, individual hospital related factors such as postoperative management protocols and background experience in minimally invasive surgery might have influenced the results but were not available. This also applies to more detailed information regarding the reasons for surgical intervention, such as iatrogenic versus spontaneous perforations and the severity of the bleeding. Lastly, no long-term survival data are available for the patients in the DUCA registry.

Future research regarding this topic would benefit from an even larger cohort study that would allow for statistical analyses corrected for bias to compare minimally invasive surgery and open surgery for esophagogastric cancer in the acute setting. However, considering the rarity of these events, larger case series are probably difficult to find. 
In conclusion, this nationwide cohort study demonstrates that acute surgical interventions for esophageal and gastric cancer are rare. For gastric cancer, minimally invasive surgery appears to be feasible and safe in the acute setting with at least comparable postoperative clinical and short-term oncological outcomes compared to open surgery, but a relatively high conversion rate.

Acknowledgements The authors would like to thank all surgeons, registrars, physician assistants and administrative nurses for collecting the data and the Dutch Upper GI Cancer Audit (DUCA) for supplying the data for this study.

\section{Compliance with ethical standards}

Disclosures Jelle P. Ruurda and Richard van Hillegersberg are proctoring surgeons for Intuitive Surgical Inc. and train other surgeons in robot-assisted minimally invasive esophagectomy. Alicia S. Borggreve and B. Feike Kingma have nothing to disclose.

Open Access This article is licensed under a Creative Commons Attribution 4.0 International License, which permits use, sharing, adaptation, distribution and reproduction in any medium or format, as long as you give appropriate credit to the original author(s) and the source, provide a link to the Creative Commons licence, and indicate if changes were made. The images or other third party material in this article are included in the article's Creative Commons licence, unless indicated otherwise in a credit line to the material. If material is not included in the article's Creative Commons licence and your intended use is not permitted by statutory regulation or exceeds the permitted use, you will need to obtain permission directly from the copyright holder. To view a copy of this licence, visit http://creativecommons.org/licenses/by/4.0/.

\section{References}

1. Haverkamp L, Seesing MF, Ruurda JP, Boone J, Hillegersberg R (2017) Worldwide trends in surgical techniques in the treatment of esophageal and gastroesophageal junction cancer. Dis esophagus. 30(1):1-7

2. Brenkman HJ, Haverkamp L, Ruurda JP, van Hillegersberg R (2016) Worldwide practice in gastric cancer surgery. World J Gastroenterol 22(15):4041-4048. https://doi.org/10.3748/wjg. v22.i15.4041

3. Biere SS, van Berge Henegouwen MI, Maas KW et al (2012) Minimally invasive versus open oesophagectomy for patients with oesophageal cancer: a multicentre, open-label, randomised controlled trial. Lancet 379(9829):1887-1892. https://doi. org/10.1016/S0140-6736(12)60516-9

4. Van Der Sluis PC, Van Der Horst S, May AM et al (2018) Robotassisted minimally invasive thoracolaparoscopic esophagectomy versus open transthoracic esophagectomy for resectable esophageal cancer a randomized controlled trial. Ann Surg. https://doi. org/10.1097/SLA.0000000000003031

5. Sihag S, Kosinski AS, Gaissert HA, Wright CD, Schipper PH (2016) Minimally invasive versus open esophagectomy for esophageal cancer: a comparison of early surgical outcomes From The Society of Thoracic Surgeons National Database. Ann Thorac Surg 101(4):1281-1289. https://doi.org/10.1016/j.athoracsur .2015 .09 .095
6. Seesing MFJ, Gisbertz SS, Goense L et al (2017) A propensity score matched analysis of open versus minimally invasive transthoracic esophagectomy in the Netherlands. Ann Surg 266(5):839-846. https://doi.org/10.1097/SLA.0000000000002393

7. Takeuchi H, Miyata H, Ozawa S et al (2017) Comparison of shortterm outcomes between open and minimally invasive esophagectomy for esophageal cancer using a nationwide database in Japan. Ann Surg Oncol 24(7):1821-1827. https://doi.org/10.1245/s1043 4-017-5808-4

8. Mamidanna R, Bottle A, Aylin P, Faiz O, Hanna GB (2012) Short-term outcomes following open versus minimally invasive esophagectomy for cancer in England: a population-based national study. Ann Surg 255(2):197-203. https://doi.org/10.1097/ SLA.0b013e31823e39fa

9. Brenkman HJF, Ruurda JP, Verhoeven RHA, van Hillegersberg R (2017) Safety and feasibility of minimally invasive gastrectomy during the early introduction in the Netherlands: short-term oncological outcomes comparable to open gastrectomy. Gastric Cancer 20(5):853-860. https://doi.org/10.1007/s10120-017-0695-8

10. Brenkman HJF, Gisbertz SS, Slaman AE et al (2017) Postoperative outcomes of minimally invasive gastrectomy versus open gastrectomy during the early introduction of minimally invasive gastrectomy in The Netherlands: a population-based cohort study. Ann Surg 266(5):831-838. https://doi.org/10.1097/SLA.00000 00000002391

11. Katai H, Mizusawa J, Katayama H et al (2017) Short-term surgical outcomes from a phase III study of laparoscopy-assisted versus open distal gastrectomy with nodal dissection for clinical stage IA/IB gastric cancer: Japan Clinical Oncology Group Study JCOG0912. Gastric Cancer 20(4):699-708. https://doi. org/10.1007/s10120-016-0646-9

12. Kim W, Kim H-H, Han S-U et al (2016) Decreased morbidity of laparoscopic distal gastrectomy compared with open distal gastrectomy for stage I gastric cancer. Ann Surg 263(1):28-35. https ://doi.org/10.1097/SLA.0000000000001346

13. Busweiler LAD, Wijnhoven BPL, van Berge Henegouwen MI et al (2016) Early outcomes from the Dutch upper gastrointestinal cancer audit. Br J Surg 103(13):1855-1863. https://doi.org/10.1002/ bjs. 10303

14. National guideline esophageal cancer (version 3.1) (2015) https:// www.oncoline.nl/oesofaguscarcinoom (accessed 21 Mar 2018)

15. National guideline gastric cancer (version 2.2) (2017) https:// www.oncoline.nl/maagcarcinoom (accessed 21 Mar 2018)

16. Markar SR, Mackenzie H, Wiggins T et al (2018) Influence of national centralization of oesophagogastric cancer on management and clinical outcome from emergency upper gastrointestinal conditions. Br J Surg 105(1):113-120. https://doi.org/10.1002/ bjs. 10640

17. Integraal Kankercentrum Nederland (IKNL). Cijfers over kanker (2018) https://www.cijfersoverkanker.nl/ (accessed 11 Dec 2018)

18. Coupland VH, Lagergren J, Lüchtenborg M et al (2013) Hospital volume, proportion resected and mortality from oesophageal and gastric cancer: a population-based study in England, 2004-2008. Gut 62(7):961-966. https://doi.org/10.1136/gutjnl-2012-303008

19. Derogar M, Sadr-Azodi O, Johar A, Lagergren P, Lagergren J (2013) Hospital and surgeon volume in relation to survival after esophageal cancer surgery in a population-based study. J Clin Oncol 31(5):551-557. https://doi.org/10.1200/JCO.2012.46.1517

20. Brusselaers N, Mattsson F, Lagergren J (2014) Hospital and surgeon volume in relation to long-term survival after oesophagectomy: systematic review and meta-analysis. Gut 63(9):1393-1400. https://doi.org/10.1136/gutjnl-2013-306074

21. Dikken JL, Dassen AE, Lemmens VEP et al (2012) Effect of hospital volume on postoperative mortality and survival after oesophageal and gastric cancer surgery in the Netherlands 
between 1989 and 2009. Eur J Cancer 48(7):1004-1013. https:// doi.org/10.1016/j.ejca.2012.02.064

22. Findlay JM, Gillies RS, Millo J, Sgromo B, Marshall RE, Maynard ND (2014) Enhanced recovery for esophagectomy: a systematic review and evidence-based guidelines. Ann Surg 259(3):413-431. https://doi.org/10.1097/SLA.0000000000000349

23. Markar SR, Schmidt H, Kunz S, Bodnar A, Hubka M, Low DE (2014) Evolution of standardized clinical pathways: refining multidisciplinary care and process to improve outcomes of the surgical treatment of esophageal cancer. J Gastrointest Surg 18(7):1238-1246. https://doi.org/10.1007/s11605-014-2520-6

Publisher's Note Springer Nature remains neutral with regard to jurisdictional claims in published maps and institutional affiliations. 